\title{
DETERMINANTS OF EMPLOYEE RETENTION IN GHANA COMMERCIAL BANK, KUMASI
}

\author{
Francis Enu-Kwesi \\ Senior Research Fellow, Institute for Development Studies, University of \\ Cape Coast \\ Frederick Koomson \\ Research Fellow, Institute for Development Studies, University of Cape \\ Coast \\ Moses Segbenya \\ Tutor, Centre for Continuing Education, University of Cape Coast \\ Elizabeth Cornelia Annan- Prah \\ Lecturer, Department of Management Studies, School of Business, \\ University of Cape Coast
}

Doi: 10.19044/elp.v1no1a6 URL:http://dx.doi.org/10.19044/elp.v1no1a6

\begin{abstract}
The study investigated the determinants of employee retention in Ghana Commercial Bank (GCB), Kumasi. Various factors that contribute to employee retention such as organizational factors, human resource factors, organizational benefits, commitment, employees' retention and job satisfaction were examined. Quantitative research design, specifically a correlational design was used. Primary data were collected from 98 employees comprising senior and junior staff, through questionnaire administration. The data were analyzed by using Spearman correlation and step-wise regression tools in Statistical Product and Service Solutions (version 17). The findings of the study revealed significant relationships among policies, job satisfaction and employee retention. Some of the specific determinants of retention were job satisfaction, training and development, communication, justice and fairness. This implies that any policy initiative that is aimed at employee retention should focus on these determinants. It is therefore recommended that employees and branch managers should cooperate and review the existing benefits by paying more attention to policies that will influence job satisfaction, training and development, communication and justice and fairness.
\end{abstract}

Keywords: Organization, goals, benefits, job, satisfaction, employee, retention, bank, Ghana 


\section{Introduction}

Employee retention, from its inception, has been well emphasized in Price and Mueller's (1986) model on retention (Bruce, 2003). This theory seems to suggest that retention efforts by management must take into consideration employees' higher needs in addition to their job context needs. This is also in line with Herzberg's (1959) two factor motivational theory which classified employee's needs as intrinsic and extrinsic needs (Mullins, 2010).

Employee retention became very important in the 1970s, when there was a rise in the formation of small and medium-size businesses as competitive employers which provided viable employment opportunities in those times (Coff, 1997). This led to the ascendancy in job mobility and voluntary job changes, and organizations began to feel the impact of the rise of voluntary employee turnover. Additionally, the power in the paternalistic "status quo" employer-employee relationship was also shifting from the employer to the employee, so a matching management tool began to be developed which was employee retention (Connel \& Philip, 2002).

In this earliest, simplest form, employee retention was a straightforward response to how employers can stem the flow. The first steps in employee retention were simply just some attempts to make the existing relationship better and more pleasant for the employee by dealing primarily with compensation, benefits, and the physical aspects of the working environment (Allan \& Sienko, 1997). Allan and Sienko also stated that by the late 1980s and early 1990s, there was a growing realisation on the part of both employers and employees that there was more to employee retention than hygiene factors. Since then, employers have been paying attention to other needs of employees such as organizational factors, human resource factors, benefit factors, job satisfaction and commitment as a way of ensuring high employee retention in their organizations (Woodruffe, 1999).

Organizations recruit human resources and train them to fit into their set-ups. They therefore go to great lengths to ensure that recruited employees are retained, by considering organizational factors, job satisfaction factors, human resource factors and employees' benefits to meet the needs of their employees (Cheng, 2004). This approach is necessitated by the fact that organizations that are unable to retain their employees have to spend lots of money and other resources to attract, recruit and train new employees which makes recruiting new employees more expensive than retaining the existing ones (Jackson \& Mathis, 2006). Such instability can lead to loss of market share and profit for these organizations, including those in the financial sector of any economy. 
The key players in a financial system include banks, non-bank financial institutions, brokerage houses, insurance companies, and regulatory institutions. Borrowers, lenders, intermediaries and regulatory institutions like the Bank of Ghana depend on the smooth running of the system, and the effectiveness of this system largely depends on recruitment and retention of competent employees (Dovlo, 2003). According to Dovlo, employee retention is an important issue in both the public and the private sectors in Ghana (Dovlo, 2003). In Ghana, the introduction of the Banking Act, 2007 (Act 673) has brought about stiff competition among the commercial banks, including Ghana Commercial Bank (GCB), which is one of the largest, if not the largest bank, in the country (Amidu, Hinson \& Mensah, 2006).

GCB offers important services such as maintenance of individual and corporate savings and current accounts, commercial and corporate lending, corporate advisory services and international trade financing. Therefore, failure of GCB as part of the system can have severe ramifications on the Ghanaian economy and the financial sector as well as on other employers.

Despite, several attempts made by the GCB to retain its workers through provision of training, development and rewards among others, the bank still lost 4.3 percent of its market share in the year 2010 (PricewaterhouseCoopers, 2010). However, there was no empirical study on whether the cause could be due to employee retention issues.

Several studies have been carried out on employee retention in developing countries. In Ghana, such studies have tended to focus on health workers and teaching staff (Dovlo, 2003). The various studies on employee retention in the developed countries dwell on organizational factors, job satisfaction and human resource factors (Cheng, 2004). Thus, there is inadequate empirical evidence on how organizational factors, human resource factors, job satisfaction and organizational benefits can influence employee retention. This paper therefore sought to examine how these factors contribute to employee retention in Ghana Commercial Bank, Kumasi.

The rest of the paper comprises theoretical and conceptual discussions on employee retention and the methodology of the study. These are followed by discussion of the results. The final section of the paper provides conclusion and policy implications or options.

\section{Theoretical and conceptual discussions on factors that affect employee retention}

Several factors, notably organizational, human resource, job satisfaction and commitment have been identified as explanatory variables for employee retention. These were captured in Price and Mueller's (1986) revised turnover model which encompassed many of the earlier retention 
factors while introducing several new ones. The model comprised determinants such as job satisfaction, distributive justice and perceived alternatives, considered as immediate causes of decisions to stay, whereas pay, promotional opportunities, constituent attachments, kinship, and organizational commitment were included as not having direct influences. Griffeth and Hom (2000) affirmed that Price and Mueller's model was based on a thorough methodology, hence its acceptance in explaining turnover processes.

According to Mitchell (2002), recruitment and development of employees costs organizations a lot of resources in terms of training and development that are aimed at equipping employees with the necessary skills, knowledge and competence to perform their current and future work assignment and challenges. Consequently, Jackson and Mathis (2006) propose that employers should strategically direct their efforts at understanding factors that influence retention and take measures to ensure that employees remain with their organizations. This view is corroborated by Hausknecht, Julianne and Vance (2008) who suggested that concerted effort is required to retain talented employees. Hausknecht et al. however, caution that there is a limit to what any organization can because retention is a complex matter that is affected by internal and external factors, and that these external factors may be beyond the organization's control. They advise that organizations can try to manage the company's climate, culture, and quality of work life to enable employees stay with the organisation.

\section{Organizational factors and employee retention}

Organizational factors are leadership style, company policies, company culture, communication and organizational justice. While Bryman (1992) showed that managers in high turnover organizations believe that employees are not to be trusted, several research findings indicate that transformational and charismatic leadership styles result in a high level of follower motivation and commitment as well as well-above-average organizational performance and attainment of organizational goals (Nanus, 1992; Steyrer, 1998). According to Olorunjuwon (2008), people often seek employment in a particular company because of its culture. However, when the culture changes, some employees become uncomfortable and leave, especially when such changes are not communicated effectively.

Communication as a component of organizational factors is important to employee retention and employers need to communicate the organizational goals, policies, visions, strategies and the job requirements to employees (Becker \& Gopinath, 2000). Becker and Gopinath emphasized that communication helps to increase employees' level of consent, 
participation, motivation, identification and building of trust, which in essence introduces elements of justice within the organization.

Greenberg (1987) argues that the major dimensions of organizational justice are distributive, interpersonal, informational and procedural and employees' perceptions of justice or injustice within the organization can result in a myriad of outcomes both positive and negative. Outcomes are affected by perceptions of organizational justice as a whole or by different factors of organizational justice (Kreik, Muchinsky \& Schreuder, 2002).

\section{Human resource factors and employee retention}

The human resource department's effort to retain the best personnel begins with recruitment. Taylor and Cosenza (1997) suggest that employers must be candid about the prevailing extrinsic factors and other details during recruitment to reduce the chances of making hiring mistakes and minimize turnover. Armstrong and Murlis (2007) also stated that an organisation's extrinsic reward system can significantly affect the performance of the employees and their desire to remain employed though money alone is not a retention factor.

For instance, Thomas and Eaglen (2000) reported that low levels of training give rise to high levels of employee turnover and that the provision of good training has a positive effect on employee retention. Hunt, Osborn and Schermerhorn (2003) also argued that a good strategy for organizations to improve workforce productivity radically, increase job satisfaction and commitment, and enhance retention is to seek to optimise their workforce through comprehensive training and development programs to ensure acquisition of requisite skills and competencies (Cheng, 2004; Cordero, 2011).

Job satisfaction, organizational benefits, commitment and employee retention

According to Bruce (2003), the theory of organizational equilibrium supports the view that job satisfaction plays a mediating role between self image, job relationship, and retention. Employee satisfaction is therefore a function of a comparison between the outcomes or rewards received and the contributions put toward the job. Intrinsic factors such as employees' opportunity for personal achievement, recognition from supervisors and growth are related to job satisfaction, while extrinsic factors such as company policy, administration, supervision, and working conditions are associated with job dissatisfaction (Robbins, 2001).

Beech and Tompkins (2002) explain that benefits are indirect rewards given to an employee or group of employees for organizational membership, and these can be categorized into two broad areas such as mandated and 
voluntary benefits. According to them, the relative importance of benefits will vary according to the specific needs of each individual, and this, in Cordero's (2011) view, can influence commitment and consequently retention.

Organizational commitment, according to Allen and Meyer (1990), is the extent to which people accept and internalize the goals of an organization and view their organizational role in terms of its contribution to those goals. Hitherto this, Mowday, Porter and Steers (1979) had explained that organizational commitment focuses on attachment to the organisation, while job satisfaction emphasised the specific task environment where duties are performed. Price and Mueller (1981) subsequently built upon these ideas and proposed a two-factor model of commitment and stated that employee commitment acts to mediate the influence of job satisfaction on employee retention.

\section{Methodology}

This study adopted the quantitative research design, specifically a correlational design to explain the relationship between factors that influence retention and employee retention, based on a sample comprising 98 senior and junior staff of GCB, Kumasi. Questionnaires which were designed with items that were measured on a scale of 1 to 5, with 1 representing low agreement while 5 represented strong agreement were used for primary data collection.

Spearman correlation analysis was used to determine the relationships between employee retention and the factors that contribute to employee retention such as human resource factors, organizational factors, organizational benefits, job satisfaction and commitment. Additionally, stepwise regression analysis was used to determine the most significant contributing factor toward employee retention.

\section{Results and discussion}

The relationships between human resource factors, organizational factors, organizational benefits, job satisfaction and commitment and employee retention were determined first. Table 1 contains the results. The means of six out of the 10 items used in the analysis were higher than the theoretical mean of three. This showed that in general the employees agreed that organizational benefits through to job satisfaction relate with employee retention. On the other hand, the employees had lower levels of agreement that leadership, justice and fairness, recruitment and selection, and reward related to employee retention, as shown by their respective means which were all lower than the theoretical mean. 
Table 1

\begin{tabular}{ccccc}
$\begin{array}{l}\text { Correlation between } \\
\text { employee retention }\end{array}$ & employees' & perceptions & on the factors & and \\
\hline Factors & Mean & SD & $\begin{array}{c}\text { Correlation with } \\
\text { employee retention }\end{array}$ & Sig. \\
\hline Organizational benefits & 3.46 & 0.76 & $0.23^{*}$ & 0.043 \\
Training and development & 3.32 & 0.95 & $0.35^{* *}$ & 0.004 \\
Policies & 3.31 & 0.92 & $0.55^{* *}$ & 0.001 \\
Communication & 3.30 & 0.95 & $0.40^{* *}$ & 0.000 \\
Commitment & 3.26 & 0.56 & $0.25^{*}$ & 0.045 \\
Job satisfaction & 3.05 & 0.52 & $0.44^{* *}$ & 0.000 \\
Leadership & 2.96 & 0.99 & 0.12 & 0.088 \\
Justice and fairness & 2.92 & 0.76 & $0.33^{* *}$ & 0.000 \\
Recruitment and selection & 2.56 & 0.85 & $0.20^{*}$ & 0.034 \\
Reward & 2.52 & 0.56 & $0.22^{*}$ & 0.045 \\
\hline
\end{tabular}

** $\mathrm{p}<0.01 \quad * \mathrm{p}<0.05$

Source: Field survey, 2012

But as seen in Table 1, all the factors, except leadership had significantly positive relationships with employee retention at either 0.01 or 0.05 alpha levels. There was a significantly strong positive relationship between policies and employee retention $(r=0.55, \mathrm{p}$-value $=0.001)$, similar to Cordero's (2011) finding $(\mathrm{r}=0.53, \mathrm{p}$-value $=0.001)$ of a strong positive and significant relationship between these factors and employee retention in the lodging industry.

Positive correlations were observed between employee retention and training and development $(\mathrm{r}=0.35, \mathrm{p}$-value $=0.004)$; communication $(\mathrm{r}=$ $0.40, \mathrm{p}$-value $=0.000)$; job satisfaction $(\mathrm{r}=0.44, \mathrm{p}$-value $=0.000)$; and justice and fairness $(r=0.33$, p-value $=0.000)$. All these are consistent with the findings of Cheng (2004) who had values from $r=0.41$ to $r=43$ as significant positive relationship between justice and fairness; training and development; communication and employee retention.

Statistically significant but relatively weak positive relationships were found between employee retention and organizational benefits $(\mathrm{r}=$ 0.23 , $\mathrm{p}$-value $=0.043)$; commitment $(\mathrm{r}=0.25$, $\mathrm{p}$-value $=0.045)$; recruitment and selection $(\mathrm{r}=0.20, \mathrm{p}$-value $=0.034)$; and reward $(\mathrm{r}=0.22$, $\mathrm{p}$-value $=$ 0.045). These results are less convincing than those of Cheng (2004) who had values from $(r=0.42)$ to $(r=0.66)$ for these relationships.

Out of the eight variables, which according to literature, had significantly positive relationship with employee retention through employees' satisfaction and commitment, only four variables were confirmed by the study to have had that significant positive relationship. These were policies, communication, justice and fairness and training and development. 
The findings mean that employees who perceived better policies, training and development, communication, job satisfaction, justice and fairness, organizational benefits, commitment, recruitment and selection and reward exhibited more positive reactions in favour of employee retention. This corroborates the findings of Cordero (2011) who concluded that how employees perceived factors in an organization would greatly influence their decision to stay or not.

An aspect of the objective of the study was to find out the most significant contributing factors to employee retention in GCB, Kumasi. This was done through step-wise multiple regression analysis, with employee retention as the dependent variable, and with reward, training and development, recruitment and selection, justice and fairness, leadership, policies, communication, organizational benefits, job satisfaction and commitment as the independent variables.

Table 2 presents the results for the step wise regression analysis.

Table 2

Contributions of the most significant factors to employee retention

\begin{tabular}{ccccccccc}
\hline $\begin{array}{c}\text { Mode } \\
1\end{array}$ & Factors & Beta & Std Error & $\mathrm{R}$ & $\mathrm{R}^{2}$ & Adjusted $\mathrm{R}^{2}$ & $\mathrm{R}^{2}$ Change & Sig. \\
\hline 1 & & & & & & & & \\
& (Constant) & 1.54 & & & & & & \\
\hline 2 & Policies & $.546^{* *}$ & .052 & .547 & .298 & .288 & & .000 \\
\hline & $\begin{array}{c}\text { Constant) } \\
\text { Policies Job }\end{array}$ & $\begin{array}{c}1.084 \\
.433^{* *}\end{array}$ & .061 & & & & & .007 \\
& satisfaction & $.207^{*}$ & .109 & .613 & .328 & .314 & .030 & .019 \\
\hline
\end{tabular}

Dependent Variable: Employee Retention $\quad * * \mathrm{p}<0.01 \quad * \mathrm{p}<0.05$

Source: Field survey, 2012

Table 2 indicates two models. In the first model, all the independent variables were excluded from the model except policies $(\propto=0.01, \mathrm{p}-$ value $=$ .000). The unique contribution of policies to employee retention was .298 with an adjusted $\mathrm{R}^{2}$ of .288 . In the second model, policies ( $\propto=0.01, \mathrm{p}-$ value $=.007)$ and job satisfaction $(\propto=0.05, \mathrm{p}-$ value $=.019)$ were considered as the most statistically significant factors that contributed more to employee retention and were not excluded from the model.

The unique contribution of the job satisfaction factor when it was considered in the second model was 0.030 with an adjusted $\mathrm{R}^{2}$ of .314 . On the whole, policies emerged as the most statistically significant factor in explaining the variance in employee retention with the other noteworthy variable being job satisfaction. Only these two factors emerged as the most statistically significant predictors of employee retention. Thus, the most 
predictive factor out of the variables in the theoretical and conceptual discussions that had significantly positive relationship with employee retention is policy. The predictive potency of policy was high when mediated by job satisfaction.

The examination of how organizational benefits, job satisfaction, commitment, human resource factors and organizational factors contribute to employee retention resulted in the following key findings. Policies of GCB, Kumasi, had a positive and significant relationship with employee retention. Only job satisfaction, training and development, communication and justice and fairness out of the eight variables had significantly positive but moderate to weak relationships with employee retention. Organizational benefits, training and development, and policy were however, perceived more strongly or positive among the eight variables of the study. Policies of GCB and job satisfaction of employees emerged as the most significant factors that influenced employee retention respectively.

The specific aspects of the policies of the bank that contributed to employee retention significantly were that the bank has a defined vision to meet its goals, an organizational structure which facilitated employees' job, periodical review of progress towards goals or targets and helpful procedures for doing things in the bank. Employees were more satisfied with the chance to know other people while on the job and the working relationship in the bank.

\section{Conclusion and policy implications}

Policies contributed strongly to employee retention, while job satisfaction, training and development, communication and justice and fairness also contributed to employee retention, but at a moderate rate. However, organizational benefits, commitment, leadership, recruitment and selection and rewards weakly contributed to employee retention. Policies of the bank and job satisfaction made the most contribution to employee retention as compared to the rest of the variables of the study. This means that GCB had appealing policies which contribute to employee retention.

The above conclusion indicates a need for certain action to occur so that employee retention would continue to be high and play its important role in the attainment of organizational goals of the Ghana Commercial Bank, Kumasi. It is suggested that with respect to policy making, management of GCB, Kumasi should focus on a review of the existing benefits available and introduce more voluntary ones like gain sharing and employee recognition schemes. This will make the bank more attractive to work with. It is also advisable for management to pay more attention to retaining the employees of the bank by focusing on policies relating to job satisfaction, training and development, communication and justice and fairness. 


\section{References:}

Allen, N. J., \& Meyer, J. P. (1990). The measurement and antecedents of affective, continuance and normative commitment to the organisation. Journal of Psychology, 63, 1-18.

Allan, P., \& Sienko, S. (1997). Comparison of contingent and core workers perceptions of their jobs characteristics and motivational properties. Journal of Advanced Management, 62 (3), 4 -7.

Amidu, M., Hinson, R., \& Mensah, R. (2006). Determinants of Ghanaian bank service quality in a universal banking dispensation. Banks System Journal, 1, 2-06.

Armstrong, M., \& Murlis, H. (2007). Reward management: A handbook of remuneration strategy and practice $\left(5^{\text {th }}\right.$ ed.). London: Kogan Page.

Becker, T. E., \& Gopinath, C. (2000). Communication, procedural justice, and employee attitudes: Relationships under conditions of divestiture. Journal of Management, 26, 63-83.

Beech, S., \& Tompkins, J. (2002). Do benefits plans attract and retain talent? Benefits Journal, 26 (10), 49-56.

Bruce, S.T. (2003). The role of community in the retention/attachment process: A qualitative study of the embeddedness model. Master of Business Administration Thesis, University of Lethbridge, Canada.

Bryman, A. (1992). Charisma and leadership in organisation. Newbury: Sage Publication.

Cheng, L. C. J. (2004). The influence of human resource management practices on retention of core employees of Australian organisations. Master of Philosophy Thesis, Murdoch University, Australia.

Coff, R.W. (1997). Human assets and management dilemmas: Coping with hazards on the road to resource- based theory. Academy of Management Journal, 22, 374- 402.

Connell, A. O., \& Phillip, J. J. (2002). Managing employee retention: A strategic approach. Butterworth: Heinemann.

Cordero, J. F. (2011). Job turnover in the lodging industry. Masters in Business Administration Dissertation. Texas Technology University, U.S.A.

Dovlo, D. (2003). The brain drain and retention of health professionals in Africa, case study prepared for a regional training conference on improving tertiary education in Sub-Saharan Africa. Things That Work Journal, Accra, September 23-25, 2003.

Griffeth, R. W., \& Hom P. W. (2000). A meta-analysis of antecedents and correlation of employee turnover: Update, moderator tests, and research implications for the next millennium. Journal of Management, 26 (3), 463488. 
Hausknecht, J., Howard, N., \& Vance, R. J. (2008). Work-unit absenteeism: Effects of satisfaction, commitment, labour market conditions and time. Academy of Management Journal, 51 (6), 1223-1245.

Hunt, J. G., Osborn, R. N., \& Schermerhorn, J. R. (2003). Organizationalbehaviour ( $8^{\text {th }}$ ed.). New York: John Wiley and Sons, Inc.

Jackson, J. H., \& Mathis, R. L. (2006). Human resource management $\left(11^{\text {th }}\right.$ ed.). New York: West Publishing Co.

Kriek, H. J., Muchinsky, P., \& Schreuder, A. (2002). Personnel psychology. Cape Town: Oxford University Press.

Mitchell, L. E. (2002). Corporate irresponsibility: America's newest export. New Haven, London: Yale University Press.

Mowday, R. T., Porter, L. W., \& Steers, R. M. (1979). The measurement of organizationalcommitment. Journal of Vocational Behaviours, 14, $224-47$.

Mullins, L. J. (2010). Management and organizationalbehaviour $\left(9^{\text {th }} \mathrm{ed}\right.$.). Harlow: Financial Times, Prentice Hall.

Nanus, B. (1992). Visionary leadership: Creating a compelling sense of direction for your organisation. Sam Francisco: Jossey - Bass.

Olorunjuwon, S. M. (2008). Using motivational strategy as panacea for employee retention and turnover in selected public and private sector organizationsin the Eastern Cape province of South Africa. Master of Commerce Dissertation, University of Fort Hare, South Africa.

Price, J. L., \& Mueller, C. W. (1981). A causal model of turnover for nurses. Academy of Management Journal, 24, 543-564.

Pricewaterhouse Coopers (2010). Banking survey. Retrieved [December, 2011] from: http//www.myjoyonline.com.

Robbins, S.P. (2001). Organizational behaviour ( $9^{\text {th }}$ ed.). New Jersey: Prentice Hall.

Steyrer, J. (1998). Charisma and the archetypes of leadership in organisation: Strategy and practice ( $5^{\text {th }}$ ed.). London: Hay Group, KoganPage.

Taylor, S. L., \& Cosenza, R. M. (1997). Internal marketing can reduce employee turnover. Supervision Journal, 3-5.

Thomas, R. L. C., \& Eaglen, A. (2000). The benefits of training in leisure retailing: A case study of McDonald's restaurants. Strategic Change Journal, 9, 333-345.

Woodruffe, C. (1999). Winning the talent war: A strategic approach to attracting, developing and retaining the best people. Chichester, UK: John Wiley \& Sons Publishers. 